\title{
Normal M-mode echocardiographic indices of Nigerian local dogs
}

\author{
Solomon Ajibola, ${ }^{1}$ Johnson Oyewale, ${ }^{2}$ Bankole Oke, ${ }^{2}$ Ladoke Durotoye, ${ }^{1}$ Timothy Adeliyi, ${ }^{1}$ Samson Rahman ${ }^{1}$ \\ ${ }^{1}$ College of Veterinary Medicine, University of Agriculture, Abeokuta; ${ }^{2}$ Faculty of Veterinary Medicine, University of \\ Ibadan, Ibadan, Nigeria
}

\section{Abstract}

There are currently no reported cardiac indices for the Nigerian dog. The aim of the study was to obtain breed specific echocardiographic indices for Nigerian local dogs. M- mode measurements of the left ventricle of 20 healthy dogs were obtained from short axis right parasternal view. The result of the study showed that posterior wall thickness in diastole and systole (PWTd, PWTs), septal wall thickness in diastole and systole (SWTd, SWTs), and left ventricular internal diameter in diastole and systole (LVIDd LVIDs) were positively and significantly correlated with body weight. Except PWT and functional indices like ejection fraction (EF) and fractional shortening (FS) whose values were higher than some breeds in literature, all other indices were within the range of values obtained in breeds previously studied. There was no significant correlation between PWTd PWTs, SWTd, SWTs and cardiac function indices such as EF, FS, enddiastolic volume (EDV), end- systolic volume (ESV) and stroke volume (SV). Although LVIDd had positive correlation with EDV, $\mathrm{ESV}$, and SV, it did not correlate with FS and EF.

The study revealed that cardiac function indices like FS and $\mathrm{EF}$ are not dependent on septal and wall thickness but rather on ventriclular volume and diameter in systole. Since cardiac function indices are also not dependent on body size, the Nigerian mongrels could serve as a useful model for cardiac studies because of their functional homogenous heart.

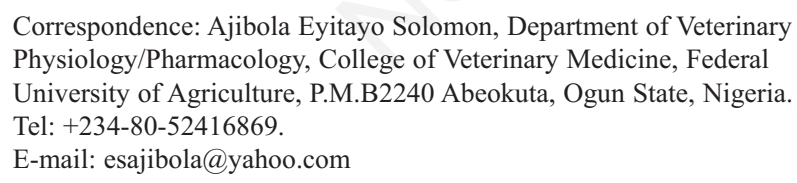
Physiology/Pharmacology, College of Veterinary Medicine, Federal University of Agriculture, P.M.B2240 Abeokuta, Ogun State, Nigeria. Tel: +234-80-52416869.

E-mail: esajibola@yahoo.com

Key words: M-mode; Echocardiographic indices; Nigeria; Local dogs.

Received for publication: 22 June 2016.

Revision received: 21 December 2016.

Accepted for publication: 22 March 2017.

CC Copyright S. Ajibola et al., 2017

Licensee PAGEPress, Italy

Journal of Biological Research 2017; 90:6107

doi:10.4081/jbr.2017.6107

This article is distributed under the terms of the Creative Commons Attribution Noncommercial License (by-nc 4.0) which permits any noncommercial use, distribution, and reproduction in any medium, provided the original author(s) and source are credited.

\section{Introduction}

Echocardiography, a safe and noninvasive technique can provide quantitative information of cardiac wall thickness, ventricular internal cavity dimensions, volume and functions. ${ }^{1,2}$ It has therefore found wide application as a research and clinical tool in both human and small animal cardiology. ${ }^{3-5}$

Echocardiographic indices have been reported for several breeds of $\operatorname{logs}^{6-8}$ and have been found to be highly breed specific and are also known to be influenced by many factors such as age, gender and body size. ${ }^{6,9,10}$ The Nigerian local dog is a docicephalic breed, native to West Africa. They are mainly kept outdoors and are traditionally used for hunting. It is potentially attractive as a research and laboratory animal because of its relative hardiness and ruggedness. The non-availability of information of the normal echocardiographic values of this breed of dog could therefore pose a serious challenge to researchers interested in the area of cardiac pharmacology and toxicology.

The high prevalence of canine infectious disease in the tropics is well known. Canine babesiosis and trypanosomiasis are two common tropical diseases that have been reported to have cardiac complications. ${ }^{11-14}$ Attempts have been made to understand the potential use of electrocardiographic and biochemical markers in diagnostic and prognostic evaluation of these diseases. ${ }^{11,12}$ Thus far studies aimed at identifying possible diagnostic and prognostic echocardiographic markers of these diseases are not available. A working knowledge of echocardiographic baseline data for this breed of dogs is therefore desirable and would assist clinicians in making rational decision on diagnosis, prognosis and treatment of these diseases.

The reason for this study is thus to establish the normal values of the left ventricular echocardiogram of this breed of dogs using 2-D guided M-mode measurement. The study is also aimed at finding out how body size affects these variables.

\section{Materials and Methods}

Twenty healthy adult (1year and above) Nigerian local dogs of mixed sexes weighing between $5 \mathrm{Kg}$ and $10 \mathrm{Kg}$ were used in this study. The dogs were randomly sourced from local breeders in Abeokuta. They were housed individually in fly proof kennel, fed twice daily with commercial food (indomie chips) and meat offal. The dogs used in this study were certified clinically healthy by physical and laboratory examination. They were also certified free of any heart disease by auscultation and electrocardiography. All the dogs had been vaccinated against canine distemper, parvovirus, leptospirosis, hepatitis at 6 weeks, 12 weeks and had received booster vaccination at one year old. This work was con- 
ducted in accordance to provisions of the animal research ethical committee of College of Veterinary Medicine, Federal University of Agriculture, Abeokuta.

Echocardiographic examination was conducted by an experienced ultrasonographer using ultrasonic scanner (Leaidal Medical, UK) with convex probe of frequency $5 \mathrm{MHz}$. The echocardiogram was taken in standing position without anesthesia. An acoustic gel (Signa gel, Parker Laboratories Inc., USA) was applied at the interface between the transducer and echo window. A 2-D guided M-mode measurements of the left ventricle at the level of papillary muscle were obtained from the short axis right parasternal view. The following indices were obtained using the inbuilt caliper of the echocardiograph; Left ventricular internal diameter in diastole (LVIDd), left ventricular internal diameter in systole (LVIDs), septal wall thickness in diastole (SWTd), septal wall thickness in systole (SWTs), posterior wall thickness in diastole (PWTd), posterior wall thickness in systole (PWTs). Left ventricular end diastolic and systolic measurements were taken at the largest and at the smallest dimensions between the interventricular septum and the left ventricular free wall respectively. Five individual measurement of each variable were obtained and averaged. All measurements are made according to standard convention. These indices were derived according to the method of Bonagura; ${ }^{3}$ Fractional shortening (FS) $=$ LVIDdLVIDs/LVIDd $\times 100 \%$; Ejection Fraction $(\mathrm{EF})=\mathrm{LVIDd}^{3}-$ LVIDs $^{3} /$ LVIDd $^{3}$. End diastolic volume (EDV) and End systolic volume (ESV) were derived from the formula of Teichholz ${ }^{15}$ as follows; EDV in $\mathrm{cm}^{3}=7$ (LVIDd) ${ }^{3} / 2.4+$ LVIDd; ESV in $\mathrm{cm}^{3}$ $=7(\text { LVIDs })^{3 / 2} 2.4+$ LVIDs. Stroke volume $(\mathrm{SV})$ in $\mathrm{cm}^{3}=\mathrm{EDV}-$ ESV. The body surface area in square meter $\left(\mathrm{m}^{2}\right)$ was derived from the formula $10.1 \times \mathrm{W}^{2 / 3} \times 10^{-4}$.

\section{Statistics}

The data obtained are expressed as mean \pm SD. Simple bivariate correlation between ventricular internal dimension indices, cardiac function indices and body weight was done using regression analysis. Correlation coefficient (r) was considered significant when $P \leq 0.05$. All analysis was done with SPSS version 16.

\section{Results}

The mean $\pm \mathrm{SD}$ and the range of echocardiographic indices of the Nigerian mongrel is shown in Table 1. Table 2 showed the correlation indices and the $\mathrm{P}$ value obtained when left ventricular dimension and thickness was correlated with body weight and cardiac function indices.

LVIDd correlated positively and significantly with SV, ESV, EDV and bodyweight. There was however no significant correlation between EF and FS.

The LVIDs correlated positively and significantly with SV, ESV, EDV and body weight. The EF and FS had high negative correlation with LVIDs $(\mathrm{P}<0.05)$.

The SWTs, PWTs, SWTd, PWTd correlated positively and significantly with body weight. These indices did not however have significant correlation with cardiac function indices like EF, FS, and indexed ESV, EDV, and SV.

\section{Discussion}

This study was similar to what has being reported in that the left ventricular internal dimension, posterior ventricular wall and septal thickness in both systole and diastole are highly dependent on body size. $3,8,10,16,17$ Ejection fraction and fractional shortening were not correlated with bodyweight in this study, which is in agreement with Bonagura, ${ }^{3}$ Lombard, ${ }^{16}$ and Crippa et al., ${ }^{6}$ who reported a lack of correlation between body size and cardiac function indices like FS and EF. The lack of dependence of these indices on body size would tend to suggest a high level of cardiac functional homogeneity in the breed studied.

Other cardiac function indices like end-diastolic volume (EDV), end-systolic volume (ESV), and stroke volume (SV) are however dependent on body size when not indexed to body surface area. ${ }^{17,8}$ The indexed EDV and ESV values obtained in this study were respectively less than $100 \mathrm{~mL} / \mathrm{m}^{2}$ and $30 \mathrm{~mL} / \mathrm{m}^{2}$ and could be described as normal. ${ }^{18}$

Table 1. M-mode echocardiographic indices of Nigerian mongrels.

\begin{tabular}{|c|c|c|c|c|c|c|}
\hline Parameters & MeantSD & Range & $\begin{array}{c}\text { Median } \\
\text { (50th percentile) }\end{array}$ & $25^{\text {th }}$ percentile & $75^{\text {th }}$ percentile & $\begin{array}{l}\text { Interquartile } \\
\text { range }\end{array}$ \\
\hline LVIDd (mm) & $20.60 \pm 4.04$ & $15-27$ & 19 & 17 & 24 & 7 \\
\hline LVIDs (mm) & $10.20 \pm 3.07$ & $6-14$ & 12 & 6 & 13 & 7 \\
\hline PWTd (mm) & $8.06 \pm 3.12$ & $5-13$ & 6 & 5 & 10 & 5 \\
\hline PWTs (mm) & $13.93 \pm 4.11$ & $9-21$ & 14 & 10 & 14 & 4 \\
\hline SWTd (mm) & $12.93 \pm 2.76$ & $9-18$ & 13 & 10 & 13 & 3 \\
\hline SWTs (mm) & $16.86 \pm 3.15$ & $14-23$ & 15 & 14 & 18 & 4 \\
\hline FS $(\%)$ & $51.13 \pm 8.98$ & $36.80-64.70$ & 48 & 45.8 & 60 & 14.2 \\
\hline $\mathrm{EF}$ & $0.86 \pm 0.06$ & $0.74-0.95$ & 0.86 & 0.84 & 0.94 & 0.1 \\
\hline $\mathrm{EDV}\left(\mathrm{mL} / \mathrm{m}^{2}\right)$ & $35.36 \pm 14.57$ & $18.14-64.20$ & 34.25 & 22.71 & 46.09 & 23.38 \\
\hline $\mathrm{ESV}\left(\mathrm{mL} / \mathrm{m}^{2}\right)$ & $6.32 \pm 4.30$ & $1.36-13.21$ & 6.35 & 1.51 & 10.70 & 9.19 \\
\hline $\mathrm{SV}\left(\mathrm{mL} / \mathrm{m}^{2}\right)$ & $29.05 \pm 10.95$ & $16.61-50.98$ & 24.84 & 21.35 & 37.46 & 16.11 \\
\hline Body weight (kg) & $8.33 \pm 3.25$ & $5.5-14.00$ & 7 & 5.5 & 12 & 6.5 \\
\hline
\end{tabular}


In spite of the relatively smaller size of the Nigerian local dog this study showed that its mean and median EDV and ESV were still respectively higher and lower than those of other outdoor dogs such as the Hungarian breed of dogs. ${ }^{8}$ Although the mean values of indexed EDV and ESV in the Nigerian dogs in this study had a strong correlation with left ventricular diameter in diastole and systole, the EDV may also be a function of higher diastolic filling pressure of the ventricle, while the relatively reduced ESV

Table 2. Correlation indices and significance level of correlation obtained between left ventricular wall thickness, dimension and cardiac function indices.

\begin{tabular}{|c|c|c|c|}
\hline $\begin{array}{l}\text { Left ventricular } \\
\text { indices }\end{array}$ & $\begin{array}{l}\text { Cardiac function } \\
\text { indices }\end{array}$ & $\begin{array}{l}\text { Correlation } \\
\text { coefficient }\end{array}$ & P value \\
\hline LVIDd & $\begin{array}{l}\text { EF } \\
\text { FS }(\%) \\
\text { SV }\left(\mathrm{mL} / \mathrm{m}^{2}\right) \\
\text { ESV }\left(\mathrm{mL} / \mathrm{m}^{2}\right) \\
\text { EDV }\left(\mathrm{mL} / \mathrm{m}^{2}\right) \\
\text { Body weight }(\mathrm{kg})\end{array}$ & $\begin{array}{c}-0.38 \\
-0.49 \\
0.81 \\
0.696 \\
0.808 \\
0.689\end{array}$ & $\begin{array}{l}0.177 \\
0.070 \\
0.000 \\
0.006 \\
0.000 \\
0.006\end{array}$ \\
\hline PWTd & $\begin{array}{l}\text { EF } \\
\text { FS }(\%) \\
\text { SV }\left(\mathrm{mL} / \mathrm{m}^{2}\right) \\
\text { ESV }\left(\mathrm{mL} / \mathrm{m}^{2}\right) \\
\text { EDV }\left(\mathrm{mL} / \mathrm{m}^{2}\right) \\
\text { Body weight }(\mathrm{kg})\end{array}$ & $\begin{array}{l}0.218 \\
0.199 \\
0.007 \\
-0.18 \\
-0.48 \\
0.605 \\
\end{array}$ & $\begin{array}{l}0.453 \\
0.495 \\
0.982 \\
0.530 \\
0.871 \\
0.022\end{array}$ \\
\hline SWTd & $\begin{array}{l}\text { EF } \\
\text { FS }(\%) \\
\text { SV }\left(\mathrm{mL} / \mathrm{m}^{2}\right) \\
\text { ESV }\left(\mathrm{mL} / \mathrm{m}^{2}\right) \\
\text { EDV }\left(\mathrm{mL} / \mathrm{m}^{2}\right) \\
\text { Bodyweight }(\mathrm{kg})\end{array}$ & $\begin{array}{c}0.308 \\
0.230 \\
0.401 \\
0.07 \\
0.323 \\
0.680\end{array}$ & $\begin{array}{l}0.284 \\
0.429 \\
0.155 \\
0.796 \\
0.261 \\
0.007\end{array}$ \\
\hline LVIDs & $\begin{array}{l}\text { EF } \\
\text { FS }(\%) \\
\text { SV }\left(\mathrm{mL} / \mathrm{m}^{2}\right) \\
\text { ESV }\left(\mathrm{mL} / \mathrm{m}^{2}\right) \\
\text { EDV }\left(\mathrm{mL} / \mathrm{m}^{2}\right) \\
\text { Body weight }(\mathrm{kg})\end{array}$ & $\begin{array}{c}-0.728 \\
-0.806 \\
0.809 \\
0.879 \\
0.721 \\
0.403 \\
\end{array}$ & $\begin{array}{l}0.001 \\
0.000 \\
0.000 \\
0.000 \\
0.002 \\
0.012\end{array}$ \\
\hline PWTs & $\begin{array}{l}\text { EF } \\
\text { FS }(\%) \\
\text { EDV }\left(\mathrm{mL} / \mathrm{m}^{2}\right) \\
\text { ESV }\left(\mathrm{mL} / \mathrm{m}^{2}\right) \\
\text { SV }\left(\mathrm{mL} / \mathrm{m}^{2}\right) \\
\text { Body weight }(\mathrm{kg})\end{array}$ & $\begin{array}{c}0.425 \\
0.375 \\
0.64 \\
0.351 \\
0.055 \\
0.839\end{array}$ & $\begin{array}{l}0.101 \\
0.153 \\
0.815 \\
0.183 \\
0.839 \\
0.000\end{array}$ \\
\hline SWTs & $\begin{array}{l}\text { EF } \\
\text { FS }(\%) \\
\text { EDV }\left(\mathrm{mL} / \mathrm{m}^{2}\right) \\
\text { ESV }\left(\mathrm{mL} / \mathrm{m}^{2}\right) \\
\text { SV }\left(\mathrm{mL} / \mathrm{m}^{2}\right) \\
\text { Body weight }(\mathrm{kg})\end{array}$ & $\begin{array}{l}0.203 \\
0.107 \\
0.410 \\
0.075 \\
0.512 \\
0.820\end{array}$ & $\begin{array}{l}0.450 \\
0.692 \\
0.115 \\
0.784 \\
0.062 \\
0.000\end{array}$ \\
\hline FS & $\begin{array}{l}\operatorname{EDV}\left(\mathrm{mL} / \mathrm{m}^{2}\right) \\
\operatorname{ESV}\left(\mathrm{mL} / \mathrm{m}^{2}\right) \\
\mathrm{SV}\left(\mathrm{mL} / \mathrm{m}^{2}\right)\end{array}$ & $\begin{array}{l}-0.517 \\
-0.855 \\
-0.386\end{array}$ & $\begin{array}{l}0.04 \\
0.000 \\
0.155\end{array}$ \\
\hline $\mathrm{EF}$ & $\begin{array}{l}\mathrm{EDV}\left(\mathrm{mL} / \mathrm{m}^{2}\right) \\
\mathrm{ESV}\left(\mathrm{mL} / \mathrm{m}^{2}\right) \\
\mathrm{SV}\left(\mathrm{mL} / \mathrm{m}^{2}\right)\end{array}$ & $\begin{array}{l}-0.48 \\
-0.81 \\
-0.292\end{array}$ & $\begin{array}{c}0.03 \\
0.00 \\
0.292\end{array}$ \\
\hline
\end{tabular}

LVIDd, left ventricular internal diameter in diastole; LVIDs, left ventricular internal diameter in systole; PWTd, posterior wall thickness in diastole; PWTs posterior wall thickness in systole; SWTd, septal wal thickness in diastole; SWTs, septal wall thickness in systole; ESV, end systolic volume indexed to body surface area; EDV, end diastolic volume indexed to body surface area; SV, stroke volume indexed to body surface area; FS, fractional shortening; EF, ejection fraction. is most likely due to the relatively higher FS and EF seen in this breed of dogs.

The mean LVID, PWT in systole and diastole in the Nigerian local dogs were comparably smaller than in other breeds available in the literature. It is however within the range described for beagles of similar mean body size. ${ }^{6}$ The Nigerian mongrel in spite of this similarity, have a comparative advantage over the beagle in terms of availability and cost of feeding and housing and can therefore replace the beagle as a universal laboratory animal model. Larger breed like German shepherd and Greyhounds have been reported to have larger values of these indices. ${ }^{10,19}$

The mean septal wall thickness in both diastole and systole in the Nigerian local dogs is outside the upper range of values for beagles and Hungarian mudis of similar mean body size. ${ }^{6,8}$ This parameter in the Nigerian breed of dog is above the mean value for German shepherds, Hungarian greyhound and Afghan hounds whose body sizes are over $100 \%$ the size of the breed studied. ${ }^{10,8}$ Lonsdale et al., ${ }^{20}$ reported that athletic dogs usually have higher value of this index. This may also be true of the average Nigerian dogs many of which are kept outdoors, extensively reared and with good hunting skills. All the cardiac function indices studied in this work has no relationship with the posterior wall and septal thickness. The enhanced thickness of interventricular septum of the Nigerian local dogs could not have accounted for the high value of systolic function indices like EF and FS.

The ejection fraction and fractional shortening obtained from the Nigerian local dogs is within the range for beagle of similar body size, ${ }^{6}$ it is also proportionately higher when compared to heavier breeds like German shepherd, Afghan hounds and Hungarian vista. ${ }^{10,8}$ Larger athletic dogs have been reported to have smaller values of these indices. ${ }^{21}$ The greater efficiency in the contractility of the heart in the small breed like the Nigerian dogs could be a compensation for the relatively small size of the left ventricle.

\section{Conclusions}

This study has shown that Nigerian breed of dog has a functionally homogenous heart and cardiac function indices like FS and EF are not dependent on septal and wall thickness but are rather dependent on volume of ventricle and its diameter in systole. The body size of the Nigerian dogs like other breeds in literature also influences the dimension indices of the left ventricle. From the findings of this study it can be concluded that Nigerian local dog like beagle is potentially suitable for use as laboratory animal in cardiovascular research. This is because the dimensional and functional indices of the left ventricle of the Nigerian dog are comparable to those of beagles of similar size.

Although this current study attempted to generate some important descriptive and correlative echocardiographic indices in Nigerian local dogs, we acknowledge our inability to employ planimetry, a supposedly more accurate method in estimation of ventricular volume as an obvious technical limitation, which can be improved upon in future studies.

\section{References}

1. Baker MI, Dalrymple GV. Biological effects of diagnostic ultrasound. Radiology 1978;126:479-83. 
2. Fortuin NJ, Hood WP Craige E. Evaluation of left ventricular function by Echocardiography. Circulation 1972:46:26-35.

3. Bonagura JD. M-Mode echocardiography, Basic principles. Vet Clin N Am-Small 1983;13:299-320.

4. Hanton G, Lodola A. Echocardiography, a noninvasive method for the investigation of heart morphology and function in laboratory dogs; 2 . Effects of minoxidil and quinidine on left ventriclular function. Lab Anim 1997:32:183-90.

5. Lang RM, Bierig M, Devereux RB. Recommendations for Chamber quantification. A report from the American society of echocardiography's guidelines and standard committee and the chamber quantification witting group, developed in conjunction with European association of echocardiography, a branch of the society of cardiology. J Am Soc Echocardiogr 2005;18:1440-63.

6. Crippa L, Ferro E, Melloni E, et al. Echocardiographic parameters and indices in the Normal beagle dogs. Lab Anim 1992;26:190-5.

7. O'Leary CA, Mackay BM, Taplin RH, Atwell RB. Electrocardiographic parameters in 14 healthy English Bull Terriers. Aust Vet J 2003;81:535-42.

8. Voros K, Hetyey C, Reiczigel J, Nagyczirok G. M-Mode and two-dimensional echocardiographic reference values for three Hungarian dog breeds; Hungarian Vizsla, Mudi and Hungarian greyhounds. Acta Vet Hung 2009;57:217-27.

9. Thomas WP, Gober CE, Jacobs GJ, et al. Recommendations for standards in transthoracic two-dimensional echocardiography in the dog and cat, Echocardiography committee of the specialty of Cardiology, American College of Veterinary Internal Medicines. J Vet Intern Med 1983;7:247-82.

10. Muzzi RA, Muzzi LA, De Araujo RB, Cherem M. 2006, Echocardiographic indices in Normal German Shepherd Dogs. J Vet Sci 2006;7:193-8.
11. Ajibola ES, Oyewale JO. Relationship between some plasma electrolytes and electrocardiographic indices of Trypanosoma brucei infected dogs. Sokoto J Vet Sci 2014;12:36-40.

12. Dvir E, Lobetti RG, Jacobson LS, et al. Electrocardiographic changes and cardiac pathology in canine babesiosis. J Vet Cardiol 2004;6:15-23.

13. Lobetti RG. Cardiac involvement in canine babesiosis Review article. J S Afr Vet Assoc 200576:4-8.

14. Morrison WI, Max M, Sayer PD, Preston JM. The pathogenesis of experimentally induced Trypanosoma brucei infection in Dogs. Am J Pathol 1981;102:168-81.

15. Teicholz, LE, Kreulen T, Herman MV, Gorlin, R. Problems in echocardiographic values determinations, EchocardiographicAngiographic correlations in presence or absence of assynergy. Am J Cardiol 1976;37:7-11.

16. Lombard CW. Normal values of canine M-mode echocardiogram. Am J Vet Res 1984;45:2013-5.

17. Gugjoo MB, Hoque M, Saxena AC, et al. Reference values of M-mode echocardiographic parameters and indices in conscious Labrador retriever dogs. Iran J Vet Res 2014;15:341-6.

18. Holt JP, Rhode EA, Kines H. Ventricular volumes and bodyweight in mammals. Am J Physiol 1968;215:708-15.

19. Page A, Edmunds G, Atwell RB. Echocardiographic values in the Greyhounds. Aust Vet J 1993;70:361-4.

20. Lonsdale RA, Labuc RH, Robertson ID. Echocardiographic parameters in training compared with non-training dogs. Vet Radiol Ultrasound 1988;39:325-30.

21. Jacobson JH, Boon JA, Bright JM. An echocardiographic studyof healthy border collies with normal reference ranges for the breed. J Vet Cardiol 2013;15:123-30. 